\title{
BMJ Open Newspaper coverage of maternal health in Bangladesh, Rwanda and South Africa: a quantitative and qualitative content analysis
}

\author{
Frey Gugsa, ${ }^{1}$ Ellora Karmarkar, ${ }^{2}$ Andrew Cheyne, ${ }^{3}$ Gavin Yamey ${ }^{4}$
}

To cite: Gugsa F,

Karmarkar E, Cheyne A, et al. Newspaper coverage of maternal health in

Bangladesh, Rwanda and South Africa: a quantitative and qualitative content analysis. BMJ Open 2016;6: e008837. doi:10.1136/ bmjopen-2015-008837

- Prepublication history and additional material is available. To view please visit the journal (http://dx.doi.org/ 10.1136/bmjopen-2015008837).

Received 20 May 2015 Revised 13 November 2015 Accepted 2 December 2015

CrossMark

\footnotetext{
${ }^{1}$ University of Pittsburgh School of Medicine, Pittsburgh, Pennsylvania, USA

${ }^{2}$ Department of Internal Medicine-Pediatrics, University of Chicago, Chicago, Illinois, USA

${ }^{3}$ Department of Policy, California Association of Food Banks, Oakland, California, USA

${ }^{4}$ Duke Global Health Institute, Duke University, Durham, North Carolina, USA
}

Correspondence to Frey Gugsa;

Frezgra@gmail.com

\section{ABSTRACT}

Objective: To examine newspaper coverage of maternal health in three countries that have made varying progress towards Millennium Development Goal 5 (MDG 5): Bangladesh (on track), Rwanda (making progress, but not on track) and South Africa (no progress).

Design: We analysed each country's leading national English-language newspaper: Bangladesh's The Daily Star, Rwanda's The New Times/The Sunday Times, and South Africa's Sunday Times/The Times. We quantified the number of maternal health articles published from 1 January 2008 to 31 March 2013. We conducted a content analysis of subset of 190 articles published from 1 October 2010 to 31 March 2013.

Results: Bangladesh's The Daily Star published 579 articles related to maternal health from 1 January 2008 to 31 March 2013, compared to 342 in Rwanda's The New Times/The Sunday Times and 253 in South Africa's Sunday Times/The Times over the same time period. The Daily Star had the highest proportion of stories advocating for or raising awareness of maternal health. Most maternal health articles in The Daily Star (83\%) and The New Times/The Sunday Times (69\%) used a 'human-rights' or 'policy-based' frame compared to $41 \%$ of articles from Sunday Times/The Times.

Conclusions: In the three countries included in this study, which are on different trajectories towards MDG 5 , there were differences in the frequency, tone and content of their newspaper coverage of maternal health. However, no causal conclusions can be drawn about this association between progress on MDG 5 and the amount and type of media coverage of maternal health.

\section{INTRODUCTION}

Millennium development goal 5

In the year 2000, United Nations (UN) member states adopted the eight Millennium Development Goals (MDGs). ${ }^{1}$ The fifth goal, MDG 5 , focuses on maternal health and has two targets. ${ }^{1}$ The first ('target $5 \mathrm{~A}^{\prime}$ ) is to
Strengths and limitations of this study

- The strengths of our study include its novelty, its multiyear analysis, the 'constructed week' sampling technique-which is more efficient and accurate and less biased than random or consecutive day sampling of newspaper contentand the rigorous content analysis based on prior work in the field.

- The cross-sectional nature of our study allowed us to examine the associations between the amount and type of media coverage of maternal health and progress on achieving Millennium Development Goal 5 (MDG 5). We used z-test analysis for proportions with a Bonferroni adjustment to compare the three countries' newspapers. However, since this was a cross-sectional study, we cannot establish the causality and temporality of the observed relationships. The associations observed could, for example, be due to unaccounted confounding factors.

- We excluded native language newspapers, newspapers without online archives and other media such as television and radio, which could have introduced bias.

- The searchable archive of South Africa's Sunday Times only goes as far back as 1 January 2008 and South Africa's The Times archive starts in October 2010. Therefore, the twofold increase in the publication rate of maternal health articles from 2010 to 2011 observed in South Africa's Sunday Times/The Times may be an artefact of our study design.

- For the period 1 January 2008 to 31 March 2013, there was insufficient information in the online newspaper archives to determine the total number of all articles in each of the three newspapers. Therefore, without such a denominator, we were unable to determine the proportion of articles in each newspaper that was focused on maternal health or the change in the proportions over time.

reduce the maternal mortality ratio (MMR) by $75 \%$ between the years 2000 and 2015 , 
and the second ('target $5 \mathrm{~B}$ ') is to achieve universal access to reproductive health by $2015 .{ }^{1}$ Progress towards MDG 5 is uneven across different countriessome countries are on track to reach the goal, some have made progress but are not on track, and some have made no progress. ${ }^{12}$ In 2005, a global movement known as Countdown to 2015 was established to track, stimulate and support country progress towards reducing child mortality and improving maternal health. ${ }^{2}$ The latest Countdown to 2015 report, published in 2012, found that out of the 75 countries that are responsible for $95 \%$ of all maternal deaths, only 9 are on track to reach MDG $5{ }^{2}$ Forty countries have made progress but are not on track and 25 countries have made insufficient or no progress. No data are available on South Sudan as separate from Sudan, as the data were collected in 2010 before the countries separated. ${ }^{2}$

In response to this ongoing crisis of avertable maternal mortality, multiple initiatives have been launched to accelerate implementation of maternal health interventions (table 1). ${ }^{1}{ }^{3}$ Countries with a high burden of maternal mortality can accelerate progress towards MDG 5 if they scale up coverage of evidence-based maternal and reproductive health interventions (eg, family planning and skilled birth attendance). ${ }^{1}$ For example, studies suggest that in the 49 lowest-income countries, scaling up reproductive health packages to $95 \%$ coverage would prevent up to $32 \%$ of maternal mortality. ${ }^{1}$ Despite this evidence, such interventions have not yet been delivered at scale, due to a combination of factors such as a lack of domestic resources, political commitment and leadership, as well as inconsistent international funding. ${ }^{1}$
The role of the media in shining a spotlight on global health challenges

The agenda setting role of news media

It is well documented that the news media can influence which public policy issues receive attention and which are ignored. Through the process of 'agenda setting', particular news stories are prioritised over other stories. This process determines which issues are presented to the public. ${ }^{4}$ For example, Thapa ${ }^{5}$ based at Family Health International in Nepal, noted that the media played a critical role through 'agenda setting' in the collective effort that led to Nepal's parliament to pass a safe abortion law in 2002. Local newspapers and magazines published evidence of the public health consequences of unsafe abortion along with their suggestions for policy and programming. ${ }^{5}$ Thapa ${ }^{5}$ wrote that 'journalists were centrally involved in these tasks'. This interaction between media and policy demonstrates how the quantity and quality of media coverage of a specific public health problem can both influence, as well as reflect, public health action directed at that problem.

\section{Framing}

The media can play an important role in influencing not only what issues are presented to mass audiences, but also how these are perceived, and what importance the public should attach to them by framing the issue in specific ways. ${ }^{6}$ The process of framing defines not only what problems are seen as important, but also their causes and potential solutions. ${ }^{6}$ As Menashe and Siegel ${ }^{6}$ describe it, "a frame is a way of packaging and positioning an issue so that it conveys a certain meaning." For example, framing maternal mortality not just as a

Table 1 Examples of recent initiatives aimed at scaling up health interventions in low-income and middle-income countries, including maternal health interventions ${ }^{1}$

\begin{tabular}{|c|c|c|}
\hline Initiative & $\begin{array}{l}\text { Launch } \\
\text { year }\end{array}$ & Objectives \\
\hline International Health Partnership & 2007 & $\begin{array}{l}\text { To focus on health systems and the need to improve aid } \\
\text { effectiveness }\end{array}$ \\
\hline $\begin{array}{l}\text { High Level Task Force on Innovative International } \\
\text { Financing for Health Systems }\end{array}$ & 2008 & $\begin{array}{l}\text { To lay out recommendations for mobilising and } \\
\text { channelling financing for health systems. It } \\
\text { recommended the creation of a joint Health Systems } \\
\text { Funding Platform by GAVI-the Vaccine Alliance, the } \\
\text { Global Fund and the World Bank }\end{array}$ \\
\hline $\begin{array}{l}\text { UN Health } 4(\mathrm{H} 4) \text {, comprising the WHO, UNFPA, } \\
\text { UNICEF and the World Bank. The } \mathrm{H} 4 \text { became the } \mathrm{H} 4 \\
\text { +after UNAIDS joined the group }\end{array}$ & 2008 & $\begin{array}{l}\text { To improve coordination at the country level and jointly } \\
\text { raise the required resources. It focuses on } 25 \\
\text { high-burden priority countries }\end{array}$ \\
\hline African Union Summit, Kampala & 2009 & $\begin{array}{l}\text { To accelerate regional commitments and efforts to } \\
\text { reduce maternal mortality in Africa }\end{array}$ \\
\hline $\begin{array}{l}\text { The Global Strategy for Women's and Children's } \\
\text { Health }\end{array}$ & 2010 & $\begin{array}{l}\text { To align all actors around a single strategic approach } \\
\text { linked to significant financial, policy and service delivery } \\
\text { commitments to achieve MDGs } 4 \text { and } 5\end{array}$ \\
\hline London Family Planning Summit* & 2012 & $\begin{array}{l}\text { To meet the family planning needs of } 120 \text { million girls } \\
\text { and women in developing countries by } 2020\end{array}$ \\
\hline
\end{tabular}

*Family Planning Summit, $2012 .{ }^{3}$

MDG, Millennium Development Goal. 
development issue but also as a human rights concern can enhance accountability for maternal deaths at the national level. ${ }^{7}$

\section{Poor media coverage reflected in lack of progress in tackling specific diseases}

There is some evidence to suggest that there is an association between media coverage of a global health problem and policy attention towards that problem. For example, Hudacek et $a l^{8}$ found that between 1981 and 2008, HIV, TB and malaria received nearly five times greater media coverage than three leading causes of child mortality: pneumonia, diarrhoea and measles. ${ }^{8}$ HIV, TB and malaria also received correspondingly greater policy attention and research funding. Similarly, Balasegaram et at found that HIV, TB and malaria received greater funding and international media coverage than three neglected tropical diseases (NTDs) human African trypanosomiasis, leishmaniasis and Chagas disease. The authors concluded that while several factors contribute to the lack of progress in drug development for NTDs, such as market failure in developing drugs, the lack of media coverage and low visibility of those diseases exacerbates the neglect. ${ }^{9}$

Ultimately, policy makers' decisions on health issues are not based solely on scientific evidence. As Hudacek et al $l^{8}$ say: "Policy decisions about funding do not occur in a sociopolitical vacuum. The media play an important role in both providing information to policy makers as well as influencing public deliberation on public health issues."

\section{How the media reflects public health policy through targeted media campaigns}

Another way in which the media influences health outcomes is through the deliberate use of targeted media campaigns. In a study in Egypt, for example, Campbell and colleagues found that one factor associated with Egypt's success in reducing its MMR was a mass media campaign focused on maternal health. ${ }^{10}$ In a second study in Egypt, Hutchinson and Meekers ${ }^{11}$ found a causal association between improved reproductive health outcomes and exposure to a multimedia communications campaign on birth spacing and family planning.

Given the growing evidence of a synergy between public health action and media attention to health challenges, media coverage of maternal health may differ in countries that are on different trajectories towards MDG 5. Our study compares media coverage of maternal health in three countries that are on different trajectories towards reaching MDG 5: Bangladesh, which is on track to achieve MDG 5; Rwanda, which is making progress but is not on track, and South Africa, which has made no progress. While national trajectory towards MDG 5 is shaped by complex factors (eg, available funds, political commitment, cultural and historical context and health infrastructure), media coverage of maternal health is one potential factor in how health policy agendas are set and funds are appropriated. Our study aimed to quantify, describe and analyse the content of national newspaper coverage of maternal health in these three countries in an effort to identify key similarities and differences in maternal health reporting. Our content analysis included an analysis of coverage of one key maternal health intervention: family planning.

\section{METHODS}

\section{Country selection}

Country progress towards Millennium Development Goals 4 and 5 (the child and maternal health goals) is tracked by the Countdown to 2015 initiative (http://www. countdown2015mnch.org/). ${ }^{2}$ The initiative categorises countries into four groups based on their progress towards MDGs 4 and 5: (A) on track; (B) some progress, but not on track; (C) insufficient progress; and (D) no progress. ${ }^{2}$ Based on the time frame that was feasible to conduct our study, we aimed to select one country from each of these four groups, based on the following inclusion and exclusion criteria that we applied to each group:

- Inclusion criteria: We included only those countries with an English language newspaper published in print and online with complete searchable archives (to allow us to conduct a newspaper content analysis in English); of these countries, we chose the country with the highest baseline MMR in 1990 (since a key aim of the MDGs was to focus attention on the worstperforming countries in 1990). ${ }^{1}$

- Exclusion criteria: We excluded countries on the World Bank 'fragile situations' list, ${ }^{12}$ as these countries face exceptional challenges in providing maternal health care $^{13}$ and in publishing newspapers without interruption. We also excluded sparsely populated countries (defined as those having a population less than 10 million in 2008), since these countries have a major advantage in scaling up maternal health services compared to countries with large populations.

Bangladesh (on track), Rwanda (making progress but not on track) and South Africa (no progress) met all of these criteria. In the 'insufficient progress' category, no country met the criteria.

Below we briefly discuss each country in turn and delineate the possible social, political, historical, health infrastructure and financial factors that could contribute to the differences in progress besides media coverage.

\section{Bangladesh is on track to meet MDG 5}

Bangladesh is a low-income country that has faced periods of political turmoil and frequent natural disasters, with nearly a third (32\%) of the population living poverty. ${ }^{14}$ In recent years, Bangladesh has had robust economic growth, averaging $6 \%$ annually between 2001 and 2012. ${ }^{14}$ Development has been swift in various social sectors, with increasing educational levels, especially for women. ${ }^{14}$ Bangladesh has also made remarkable progress towards achieving MDG 5. Between 1990 and 2010, the MMR fell from 800 to 240 deaths/100 000 live-births with an average annual decline of $5.9 \%{ }^{2}$ 


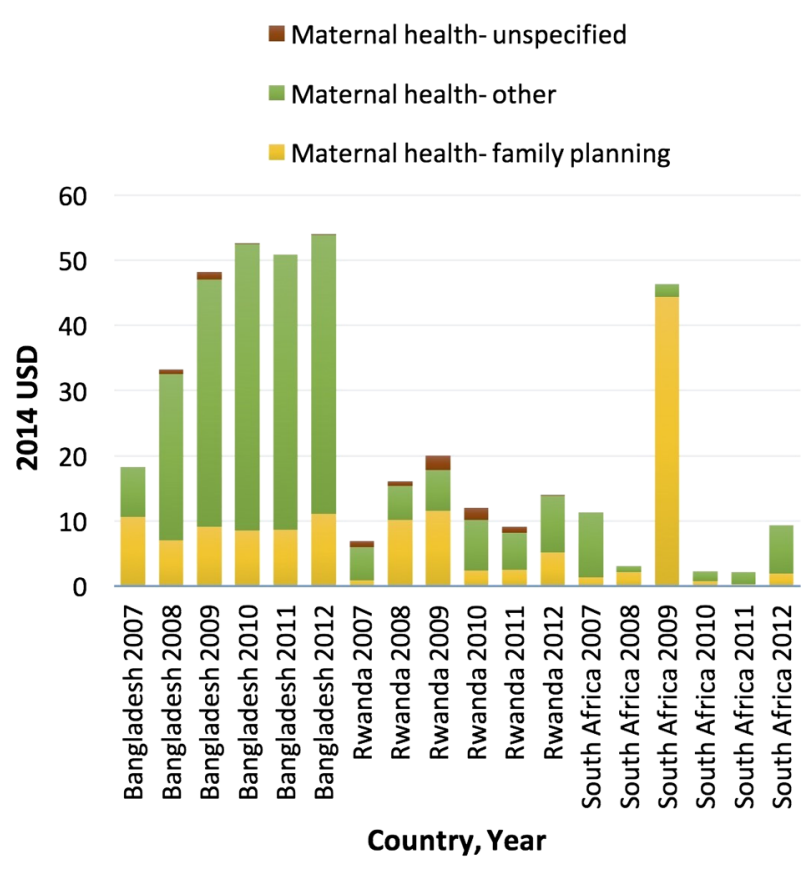

Figure 1 Development Assistance for Health (DAH) for Bangladesh, Rwanda, and South Africa between 2007 and 2012.

Given this rapid rate of decline, the country should reach its target MMR of under 200/100 000 live-births by $2015 .^{2}$

This progress was achieved through factors such as increased access to family planning services, comprehensive emergency obstetric care, safe abortion practices and improved education of women. ${ }^{2}{ }^{14}$ In addition, as shown in figure 1, Bangladesh is a major recipient of development assistance for health (DAH) for maternal health, and from 2007 to 2010 there was a sharp rise in DAH for maternal health channelled to the country. ${ }^{15}$ This rise in DAH may have contributed to its accelerated progress towards reaching MDG 5.

\section{Rwanda has made progress but is not on track to meet MDG 5}

The 1994 genocide in Rwanda destroyed the country's healthcare system and drove hundreds of medical workers into exile, which in turn affected maternal morbidity and mortality. ${ }^{16}$ Rwanda launched a community-wide health insurance scheme to address the health system crisis, supported by the Global Fund to
Fight AIDS, Tuberculosis and Malaria (GFATM), and this scheme made care affordable for many women. ${ }^{16} \mathrm{In}$ addition, voluntary community health workers (CHWs) trained in basic maternal health services are playing a crucial role in reducing Rwanda's MMR. ${ }^{16}{ }^{17}$ The CHWs provide family planning education and services, and monitor pregnant women within their community. ${ }^{17}$ As shown in figure 1, from 2007 to 2009, there was a rise in DAH for maternal health channelled to Rwanda. ${ }^{15}$ This rise in DAH for maternal health might have potentially contributed to accelerating progress towards MDG 5. Between 1990 and 2010, the MMR in Rwanda fell from 910 to 340 deaths per 100000 live-births, a decrease of over $50 \%$, with an annual average fall of $4.9 \% .^{2}$ However, this rate of decline is not fast enough to meet MDG 5 by 2015 .

\section{South Africa has made no progress towards achieving MDG 5}

The MMR in South Africa increased from 1990 to 2010 , from 250 to 300 deaths $/ 100000$ live-births. ${ }^{2}$ The country has made no progress towards achieving MDG 5 and will not achieve its 2015 target of 38 deaths per 100000 live-births. ${ }^{18}$ The leading causes of maternal death in South Africa are direct obstetric causes and non-pregnancy-related causes, such as HIV/AIDS. ${ }^{18}$ HIV/AIDS increases the risk of maternal death 10-fold in South Africa. ${ }^{18}$

South Africa is an upper middle-income country and the country's constitution guarantees the right to healthcare. ${ }^{19} 20$ As shown in figure 1 , while South Africa did receive DAH for maternal health over the time period of this study, nearly all of this was for family planning rather than for other maternal health services. ${ }^{15}$ Nevertheless, the nation's health system faces many challenges. These include lack of medical supplies and equipment; poor quality of care; lack of accountability of health professionals and public administrators; and a high burden of disease, particularly HIV infection. ${ }^{18} 1921$ These challenges have been major obstacles to improving maternal health outcomes.

\section{Newspaper selection}

The media refers to channels of mass communication, including radio, television and newspapers. Table 2 shows the proportion of the population that has access to these three channels, based on data from recent

\begin{tabular}{|c|c|c|c|c|c|c|}
\hline \multirow[b]{2}{*}{ Country } & \multicolumn{2}{|c|}{$\begin{array}{l}\text { Proportion (\%) } \\
\text { owning a radio }\end{array}$} & \multicolumn{2}{|c|}{$\begin{array}{l}\text { Proportion (\%) } \\
\text { owning a television }\end{array}$} & \multicolumn{2}{|c|}{$\begin{array}{l}\text { Proportion (\%) accessing a } \\
\text { newspaper at least once a week }\end{array}$} \\
\hline & Urban & Rural & Urban & Rural & Urban & Rural \\
\hline Bangladesh & 7 & 9 & 70 & 30 & 15 & 3 \\
\hline Rwanda & 76 & 60 & 28 & 2 & 28 & 2 \\
\hline South Africa & 80 & 69 & 75 & 41 & 54 & 23 \\
\hline
\end{tabular}


demographic and health surveys in our three focus countries. $^{22-25}$ We chose to study newspapers, rather than radio and television, since newspaper articles are much more likely to be archived and accessible to researchers. It would not have been possible for us to obtain complete archives of radio and television coverage in this study.

Analysis of print media is a common approach in health research given the wide availability and accessibility of print archives. ${ }^{9}$ Previous research has suggested that while newspapers and television are likely to reach different audiences, their coverage of a particular health issue is similar. For example, one study of news coverage of alcohol found a very strong correlation between the number of alcohol-related television stories and the number of alcohol-related newspaper stories over a given time period. ${ }^{26}$ In addition, other studies show no difference in the perceived importance of an issue between different forms of media, such as newspaper versus television. ${ }^{27}$ Thus consumption of print media is likely to have similar weight to television in highlighting important health issues. Print media also has the advantage of being reflective of the political elite. While most of the population in Rwanda and Bangladesh access news information through television, consumers of print media are more likely to be educated, and could have political and financial resources at their disposal to invest in critical issues. Finally, print media in emerging economies is perceived as being a key tool for agenda-setting. ${ }^{28}$

For each country, we selected the highest circulation English language newspaper published in print and on the Internet. We selected English language newspapers in order to standardise the analysis and enable comprehensive coverage within the study's time period. In Bangladesh, while English language does not have an official status, it is widely used across government, media and education. ${ }^{29}$ In both Rwanda ${ }^{23}$ and South Africa, ${ }^{24}{ }^{25}$ English is one of the official languages. To make the newspapers relatively comparable between countries, we selected a daily newspaper for each country. However, if the highest circulation English language newspaper was not a daily newspaper, we combined it with an affiliated sister newspaper in order to have at least 6-7 days per week of articles to analyse.

For Bangladesh, we selected The Daily Star (a daily newspaper). The Daily Star is seen as a high-quality leading English newspaper within Bangladesh. ${ }^{30}$ For Rwanda, we selected The New Times (published 6 days of the week, Monday through Saturday) and we included The New Times' sister newspaper, Rwanda's The Sunday Times, for Sunday coverage. Throughout this research article, when we refer to The New Times/The Sunday Times, we are referring to Rwanda's The New Times and its sister paper The Sunday Times. A Rwandan countrybased analysis found that out of all print media and television within Rwanda, The New Times had the greatest diversity in sources as well as the largest number of news items. $^{31}$ For South Africa, we selected Sunday Times (published Sundays, with a searchable archive that goes only as far back as 1 January 2008). To achieve 6 days per week of articles to analyse, we included the Sunday Times' sister paper, The Times, which is published five times per week, Monday to Friday. The Times is fully archived from 1 October 2010 onwards. Throughout this research article, Sunday Times/The Times refers to the South Africa's Sunday Times and its sister paper The Times. Previous studies using the highest circulation Sunday Times have emphasised its influence in South African politics and highlighted it as a form of 'elite or opinion-forming media'. ${ }^{32}$

\section{Search strategy}

We searched the electronic archives of each country's newspapers described above from 1 January 2008 to 31 March 2013. We chose a 1 January 2008 start date because the searchable archive of South Africa's Sunday Times only goes as far back as 1 January 2008. We searched for articles on maternal health (including family planning) using the strategy detailed in online supplementary appendix A. The collected articles were entered on an Excel spreadsheet.

\section{Sampling strategy}

We used a 'constructed week' sampling technique, in which "sample dates are stratified by day of the week to account for systematic variation due to day of the week." ${ }^{33}$ Thus the final sample represents all 7 days of the week. This technique is more efficient, more accurate and less biased than random or consecutive day sampling of newspaper content. ${ }^{33}$ To construct comparable samples from each country, we created 12 constructed weeks per year per country between 1 October 2010 (the starting date of the archive of South Africa's The Times) and 31 March 2013. To construct 1 week from 1 month, we randomly selected one Monday from all four Mondays of that month, one Tuesday from all Tuesdays, one Wednesday from all Wednesdays, and so on. We included any article published during the days that were randomly selected. If no relevant maternal health articles were published, none were analysed for that date. As a result, there is variation in the number of articles sampled for analysis from each newspaper. Through this 'constructed week' sampling method, we sampled 75 articles from The Daily Star (Bangladesh), 64 articles from Rwanda's The New Times/The Sunday Times and 51 articles from South Africa's Sunday Times/The Times - a total of 190 articles.

\section{ANALYSIS}

\section{Quantitative analysis}

We quantified the number of articles on maternal health published annually for each newspaper. For the content analysis, we coded the number and nature of the articles, type of article (eg, news vs editorial), 


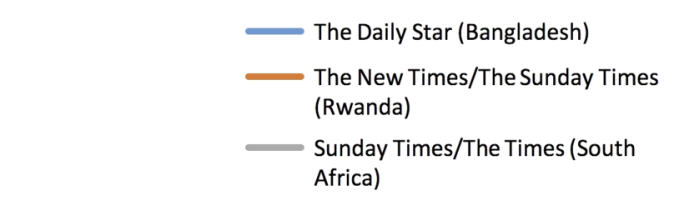

250

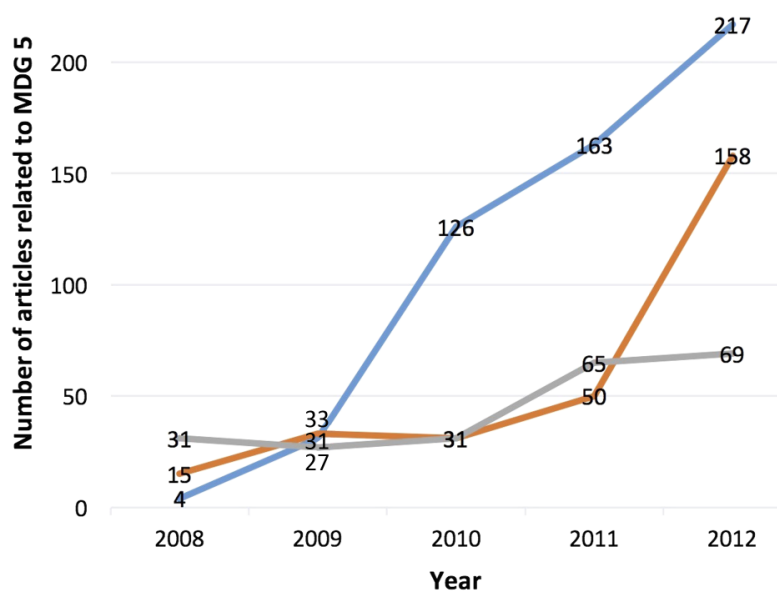

Figure 2 Number of articles related to MDG 5 (maternal health) published between 1 January 2008 and 31 December 2012 in The Daily Star (Bangladesh), The New Times/The Sunday Times (Rwanda) and Sunday Times/The Times (South Africa). From 1 January 2009 to 31 December 2010, Bangladesh's The Daily Star showed the highest rate of increase in the annual number of articles published related to maternal health. From 1 January 2011 to 31 December 2012, Rwanda's The New Times/The Sunday Times showed the highest rate of increase. South Africa's Sunday Times/The Times had the slowest rate of increase from 1 January 2008 to 31 December 2012. MDG 5, Millennium Development Goal 5.

purpose, regional focus and length. We used z-test analysis for proportions with a Bonferroni adjustment to compare the three countries' newspapers.

\section{Qualitative framework analysis}

We used the context of 'agenda-setting, ${ }^{8}$ to identify the three main frameworks used to present maternal health issues: (A) 'rights-based' frameworks describing maternal health as a human right; ${ }^{7}$ (B) 'policy-based' frameworks presenting maternal health challenges as part of economic or social development with specific policy solutions; and (C) frameworks discussing maternal health as an 'ethical' or 'moral' issue. ${ }^{8}$ We quantified the frequency of these frameworks in each newspaper, whether written directly by the journalist or quoted from an interview. We coded for narrative elements, story tone (negative, neutral, positive, or mixed), protagonist, antagonist and story dimensions (statistics, facts, aetiologies); solutions; and target audience. We also assessed the frequency of articles covering roundtables, seminars or discussions about maternal health issues that were hosted by the newspaper or created in collaboration with other organisations. Finally, we noted whether articles directly mentioned MDG 5 in their analysis of maternal health.

\section{ASSESSIMENT OF RELIABILITY}

Two coders (FG and EK) developed the codebook from relevant existing work, ${ }^{8}$ supplemented with additional themes that emerged from the three newspapers (see online supplementary appendix B). We followed an iterative process ${ }^{34}$ of reading randomly selected articles, assessing themes and adjusting the codebook until we achieved inter-rater reliability (Cohen's $\kappa>0.82$ ). All articles were recoded using the finalised codebook.

\section{RESULTS}

\section{Volume and frequency of articles}

From 1 January 2008 to 31 March 2013, The Daily Star (Bangladesh) published 579 articles on maternal health, compared to 342 articles in Rwanda's The New Times/The Sunday Times and 253 in South Africa's Sunday Times/The Times. The rate of increase in the number of maternal health articles published annually also differed markedly between the newspapers (figure 2). In Bangladesh's The Daily Star, the number of articles on maternal health rose from only four articles in 2008 to 217 articles in 2012. Rwanda's The New Times/The Sunday Times also sharply increased its coverage of maternal health, from 15 articles in 2008 to 158 articles in 2012. South Africa's Sunday Times/The Times had the slowest rate of increase, from 31 articles in 2008 to 69 articles in 2012.

\section{Quantitative and qualitative content analysis}

Below are the results of our analysis of articles sampled through a constructed-week sampling method. The timeframe for the analysis was 1 October 2010 to $31 \mathrm{March}$ 2013.

\section{Article type}

A significantly higher proportion of the maternal health articles in South Africa's Sunday Times/The Times and Rwanda's The New Times/The Sunday Times were news coverage of specific events, meetings and conferences (88\% and $86 \%$ of articles from the two newspapers, respectively, compared to $48 \%$ of articles in Bangladesh's The Daily Star ( $\mathrm{p}<0.05$; table 3$)$ ). None of the articles on maternal health in the South African and Rwandan papers were in-depth reports. In comparison, about 1 of every 7 (13\%) maternal health articles published in Bangladesh's paper involved in-depth coverage of maternal health issues, and were usually published in the paper's health section (a section called 'Star Health').

About 4 of every $10(37 \%)$ maternal health articles published in Bangladesh's The Daily Star were opinionbased articles (letters, opinions and Op-Eds), a significantly higher proportion than the articles in Rwanda's The New Times/The Sunday Times (8\%) or South Africa's Sunday Times/The Times $(12 \%) \quad(\mathrm{p}<0.05 ;$ table 3$)$. 
Table 3 Quantitative analysis of article type, purpose, focus country and story length in articles related to MDG 5 in The Daily Star (Bangladesh), The New Times/The Sunday Times (Rwanda) and Sunday Times/The Times (South Africa)

\begin{tabular}{|c|c|c|c|c|c|c|}
\hline & \multicolumn{2}{|c|}{$\begin{array}{l}\text { The Daily Star } \\
\text { (Bangladesh) }\end{array}$} & \multicolumn{2}{|c|}{$\begin{array}{l}\text { The New Times/ } \\
\text { The Sunday Times } \\
\text { (Rwanda) }\end{array}$} & \multicolumn{2}{|c|}{$\begin{array}{l}\text { Sunday Times/ } \\
\text { The Times } \\
\text { (South Africa) }\end{array}$} \\
\hline & $(n=75)$ & $(\%)$ & $(n=64)$ & $(\%)$ & $(n=51)$ & $(\%)$ \\
\hline \multicolumn{7}{|l|}{ Article type } \\
\hline News* & 36 & 48 & 55 & 86 & 45 & 88 \\
\hline Letters or Op-Eds* & 28 & 37 & 5 & 8 & 6 & 12 \\
\hline Health section & 10 & 13 & 2 & 3 & 0 & 0 \\
\hline Editorial & 1 & 1 & 2 & 3 & 0 & 0 \\
\hline \multicolumn{7}{|l|}{ Purpose } \\
\hline Advocacy/awareness* & 46 & 61 & 25 & 39 & 20 & 39 \\
\hline Event coverage & 26 & 35 & 38 & 59 & 29 & 57 \\
\hline Other & 3 & 4 & 1 & 2 & 2 & 4 \\
\hline \multicolumn{7}{|l|}{ Focus country } \\
\hline Own country* & 70 & 93 & 58 & 91 & 30 & 59 \\
\hline Other country & 5 & 7 & 6 & 9 & 21 & 41 \\
\hline \multicolumn{7}{|l|}{ Story length } \\
\hline $0-500$ words & 52 & 69 & 44 & 69 & 33 & 65 \\
\hline $501-1000$ words & 12 & 16 & 17 & 27 & 16 & 31 \\
\hline $1001+$ words & 11 & 15 & 3 & 5 & 2 & 4 \\
\hline $\begin{array}{l}\text { MDG } 5 \text { explicitly mentioned } \\
\text { in the article* }\end{array}$ & 27 & 36 & 6 & 9 & 0 & 0 \\
\hline
\end{tabular}

Opinion-based articles in The Daily Star often included strong opinions that supported or challenged the government's stance on particular policies, and shaped perceptions of solutions. For example, a letter writer in The Daily Star called for action on MDG 5:

...If we want to achieve the MDG-5 by the stipulated time, the government, national and international organisations including UN organisations should come forward and work hard together and invest in safe motherhood programmes to drastically reduce the rate of maternal deaths. ${ }^{35}$

\section{Story purpose}

A significantly greater proportion of maternal articles in The Daily Star were advocating for or raising awareness of maternal health $(61 \%)$ than in Rwanda's The New Times/ The Sunday Times (39\%) and South Africa's The Sunday Times/The Times (39\%) $(\mathrm{p}<0.05$; table 3$)$.

\section{Regional focus}

The Daily Star and Rwanda's The New Times/The Sunday Times had a significantly higher proportion of articles that emphasised local rather than international maternal health issues (93\% and 91\%, respectively), compared to South Africa's Sunday Times/The Times (59\%) ( $<<0.05$; table 3). In comparison, about 4 of every $10(41 \%)$ maternal health articles in South Africa's Sunday Times/ The Times focused on other countries; for example, in 2012, about 1 of every 5 (22\%) maternal and reproductive health articles covered US election debates on abortion and contraception.

\section{Article length}

There was no significant difference in the length of the articles between the three sampled newspapers.

\section{MDG 5}

Over one third (36\%) of articles from Bangladesh's The Daily Star explicitly discussed MDG 5 in the context of improving maternal health, compared to just $9 \%$ of articles from Rwanda's The New Times/The Sunday Times and no articles in South Africa's Sunday Times/The Times $(\mathrm{p}<0.05$; table 3$)$.

\section{Qualitative framework analysis}

\section{Framing}

Most maternal health articles in Bangladesh's The Daily Star and Rwanda's The New Times/The Sunday Times used rights-based or policy-based framing $(83 \%$ and $69 \%$, respectively). In contrast, only a minority of articles $(41 \%)$ in South Africa's Sunday Times/The Times used such framing (table 4). The quotation below gives an example of rights-based framing, from journalist Doreen Umutesi in Rwanda's The New Times:

...with the establishment of reproductive health services that are youth-friendly, Rwanda is venturing into a path that will see the creation of a generation that is informed about their reproductive health rights. ${ }^{36}$ 
Table 4 Qualitative analysis of the main theme, story tone, proponent and plan of action in articles related to MDG 5 in The Daily Star (Bangladesh), The New Times/The Sunday Times (Rwanda) and Sunday Times/The Times (South Africa)

\begin{tabular}{|c|c|c|c|c|c|c|}
\hline & \multicolumn{2}{|c|}{$\begin{array}{l}\text { The Daily Star } \\
\text { (Bangladesh) }\end{array}$} & \multicolumn{2}{|c|}{$\begin{array}{l}\text { The New Times/ } \\
\text { The Sunday Times } \\
\text { (Rwanda) }\end{array}$} & \multicolumn{2}{|c|}{$\begin{array}{l}\text { Sunday Times/The } \\
\text { Times } \\
\text { (South Africa) }\end{array}$} \\
\hline & $(n=75)$ & $(\%)$ & $(n=64)$ & $(\%)$ & $(n=51)$ & $(\%)$ \\
\hline \multicolumn{7}{|l|}{ Main theme } \\
\hline Human rights frames & 29 & 39 & 18 & 28 & 13 & 25 \\
\hline Policy-based frames & 33 & 44 & 26 & 41 & 8 & 16 \\
\hline Moral or ethical frames & 11 & 15 & 13 & 20 & 20 & 39 \\
\hline Economic & 2 & 2 & 2 & 3 & 4 & 8 \\
\hline Personal/heroic & 0 & 0 & 2 & 3 & 4 & 8 \\
\hline Other theme & 0 & 0 & 3 & 5 & 2 & 4 \\
\hline \multicolumn{7}{|l|}{ Story tone } \\
\hline Positive & 32 & 43 & 25 & 39 & 7 & 14 \\
\hline Negative & 22 & 29 & 15 & 23 & 32 & 63 \\
\hline Mixed & 16 & 21 & 16 & 25 & 8 & 15 \\
\hline Neutral & 5 & 7 & 8 & 1 & 4 & 8 \\
\hline \multicolumn{7}{|l|}{ Proponent $^{\star}$} \\
\hline Government & 27 & 36 & 35 & 55 & 11 & 22 \\
\hline Organisation, the UN, the WHO & 23 & 31 & 18 & 28 & 5 & 10 \\
\hline Health professional & 5 & 7 & 14 & 22 & 4 & 8 \\
\hline Activist & 5 & 7 & 8 & 13 & 5 & 10 \\
\hline Patient & 2 & 3 & 1 & 2 & 9 & 18 \\
\hline \multicolumn{7}{|l|}{ Plan of action* } \\
\hline Political will & 49 & 65 & 20 & 31 & 7 & 14 \\
\hline Increase funding & 44 & 59 & 26 & 41 & 13 & 25 \\
\hline Create awareness & 28 & 37 & 24 & 38 & 5 & 10 \\
\hline
\end{tabular}

Policy-based framing focused on legislative and programmatic initiatives. For example, Dr Kashfia Keya wrote in The Daily Star.

Bangladesh has made remarkable achievements in reproductive health and reducing maternal mortality... however, addressing workforce need is critical, with particular attention to a defined role for midwives in regulation, education and deployment. ${ }^{37}$

South Africa's Sunday Times/The Times often used moral or ethical framing (39\% of articles); such framing was less common in The Daily Star (15\% of articles) and Rwanda's The New Times/The Sunday Times (20\% of articles) (table 4). For example, an article in South Africa's Sunday Times described moral shaming of nurses who did not protect the health of patients:

South African nurses found guilty of offences such as fraud, assaulting patients, and giving them the wrong medicines, are, for the first time, being named and shamed... at least 21 (cases) involved negligence in treating women in labour. ${ }^{38}$

\section{Story tone}

Nearly two-thirds (63\%) of South Africa's Sunday Times/The Times maternal health articles had a negative tone compared to $29 \%$ of The Daily Star articles and $23 \%$ of Rwanda's The New Times/The Sunday Times articles (table 4).

\section{Protagonists}

The Daily Star and Rwanda's The New Times/The Sunday Times frequently cited prominent global organisations such as the UN or WHO or government officials as key advocates for maternal health issues (table 4). For example, an article in Rwanda's The New Times/The Sunday Times linked the Rwandan president, President Kagame, and Rwandan policy to the global movement for maternal health:

President Kagame has taken the lead...at the launch of the United Nations Secretary General's Global Strategy on Women's and Children's Health, he committed to increasing health sector spending from $10.9 \%$ to $15 \%$ by 2012. The setting of strong objectives and tangible deadlines is crucial for the improvement of health outcomes for women and children. ${ }^{39}$

South Africa's Sunday Times/The Times was less likely to identify high-profile protagonists at the international level and more likely to mention a lower profile protagonist for maternal health, usually as part of a local or national programme (table 4). 
Table 5 Qualitative analysis of articles on maternal health and family planning in The Daily Star (Bangladesh), The New Times/The Sunday Times (Rwanda) and Sunday Times/The Times (South Africa)

\begin{tabular}{|c|c|c|c|c|c|c|}
\hline & \multicolumn{2}{|c|}{$\begin{array}{l}\text { The Daily Star } \\
\text { (Bangladesh) }\end{array}$} & \multicolumn{2}{|c|}{$\begin{array}{l}\text { The New Times/ } \\
\text { The Sunday } \\
\text { Times (Rwanda) }\end{array}$} & \multicolumn{2}{|c|}{$\begin{array}{l}\text { Sunday Times/ } \\
\text { The Times } \\
\text { (South Africa) }\end{array}$} \\
\hline & $(n=75)$ & $(\%)$ & $(n=64)$ & $(\%)$ & $(n=51)$ & $(\%)$ \\
\hline \multicolumn{7}{|l|}{ Causes of high maternal mortality ratio* } \\
\hline Complications of pregnancy and childbirth & 39 & 52 & 31 & 48 & 12 & 24 \\
\hline Lack of access to healthcare services & 22 & 29 & 10 & 16 & 6 & 12 \\
\hline Early childbearing & 7 & 9 & 2 & 3 & 0 & 0 \\
\hline Unsafe abortion & 3 & 4 & 5 & 8 & 3 & 6 \\
\hline Indirect causes & 0 & 0 & 5 & 8 & 3 & 6 \\
\hline \multicolumn{7}{|l|}{ Interventions to improve maternal health* } \\
\hline Skilled care at birth & 34 & 45 & 28 & 44 & 6 & 12 \\
\hline Reproductive healthcare & 17 & 23 & 12 & 19 & 5 & 10 \\
\hline Health system strengthening & 17 & 23 & 21 & 33 & 6 & 12 \\
\hline Empowerment of women & 12 & 16 & 5 & 8 & 4 & 8 \\
\hline Ending child marriage & 8 & 11 & 2 & 3 & 0 & 0 \\
\hline Access to safe abortion & 2 & 3 & 6 & 9 & 2 & 4 \\
\hline \multicolumn{7}{|l|}{ Need for family planning ${ }^{*}$} \\
\hline Slowing population growth & 18 & 24 & 9 & 14 & 4 & 8 \\
\hline Preventing pregnancy-related risks & 12 & 16 & 11 & 17 & 2 & 4 \\
\hline Reducing adolescent pregnancies & 11 & 15 & 13 & 20 & 10 & 20 \\
\hline Helping to prevent HIV/AIDS & 0 & 0 & 7 & 11 & 2 & 4 \\
\hline \multicolumn{7}{|l|}{ Barriers to family planning* } \\
\hline Lack of advocacy and awareness & 26 & 35 & 11 & 17 & 11 & 22 \\
\hline Financial barriers to accessing family planning & 16 & 21 & 7 & 11 & 3 & 6 \\
\hline Lack of political will/lack of public funding & 16 & 21 & 1 & 2 & 3 & 6 \\
\hline Religious/cultural leaders or beliefs & 2 & 3 & 8 & 13 & 6 & 12 \\
\hline \multicolumn{7}{|c|}{ Causes of maternal deaths/lack of progress on MDG $5^{\star}$} \\
\hline Lack of funding or other resources & 9 & 12 & 8 & 13 & 6 & 12 \\
\hline Lack of awareness & 5 & 7 & 9 & 14 & 4 & 8 \\
\hline Lack of political will & 5 & 7 & 6 & 9 & 6 & 12 \\
\hline \multicolumn{7}{|c|}{ Causes of improved maternal health/positive progress on MDG $5^{*}$} \\
\hline Political will & 14 & 19 & 9 & 14 & 0 & 0 \\
\hline Increased funding & 11 & 15 & 17 & 27 & 0 & 0 \\
\hline Creating awareness & 11 & 15 & 18 & 28 & 0 & 0 \\
\hline
\end{tabular}

\section{Panel discussions}

Unlike the South African and Rwandan newspapers that we analysed, Bangladesh's The Daily Star frequently organises roundtables, seminars and discussions with experts and organisations to raise awareness of important national issues, ${ }^{40}$ including maternal health. Three per cent of articles we sampled from The Daily Star on maternal health reported on these special roundtables, seminars and discussions.

\section{Causes of maternal deaths}

Across all three newspapers, complications of pregnancy and childbirth and poor access to healthcare were the most commonly identified causes of maternal mortality (table 5).

\section{Solutions for improving maternal health}

Increasing skilled attendance at birth and improving access to reproductive healthcare were the most commonly mentioned interventions across all three newspapers.

\section{Family planning}

Articles about family planning in The Daily Star were more likely than those in the other two newspapers to mention family planning as a method to slow population growth rather than as a means to improve maternal health (table 5):

The government will recruit around 13,000 field-level officials in the family planning department with a view to address rise in population, a major concern of the country... ${ }^{41}$

In contrast, both Rwanda's The New Times/The Sunday Times and South Africa's Sunday Times/The Times were more likely to emphasise family planning as a means to reduce adolescent pregnancy. For example, in an article from Rwanda's The New Times/The Sunday Times 
discussing family planning and adolescent health, Victoria Akyeampong, UN Population Fund (UNFPA) Country Director, commented:

...the issue of adolescent teenage pregnancies cannot be ignored and, therefore, it is very important that we target problems that address sexuality needs among Rwanda's youth. $^{36}$

In Rwanda, family planning was also discussed in the context of abortion, with a spike in abortion-related articles in 2012. About 1 of every 6 (15\%) maternal health articles published in 2012 from Rwanda's The New Times/ The Sunday Times discussed abortion, such as a statement from Chantal Umuhoza, the Coordinator of Rwanda's Safe Abortion Action Fund:

We should have a safe legal environment for safe abortion...It's every woman's right to terminate a pregnancy when they decide to. ${ }^{42}$

\section{Barriers}

All three newspapers published articles that mentioned limited awareness, poor advocacy and financial barriers as the main obstacles to accessing family planning (table 5).

\section{DISCUSSION}

Our study of newspaper of maternal health in three countries that have made varying progress towards MDG 5-Bangladesh (on track), Rwanda (making progress, but not on track) and South Africa (no progress)found several important differences between each country's newspapers in the quantity and content of articles on maternal health. In particular, Bangladesh's newspaper published articles on maternal health more frequently than the other newspapers, and these articles were more likely to be in-depth reports and opinionbased articles (letters, opinions and Op-Eds). Our findings suggest that there is an association between the amount and type of media coverage of maternal health and progress on MDG 5. However, this was a crosssectional study and therefore we cannot infer causality.

\section{Differences in volume and frequency of publication}

The Daily Star of Bangladesh had the greatest volume and frequency of maternal health reporting during the study period, while South Africa's Sunday Times/The Times had the lowest volume and frequency of maternal health coverage. Prior research has shown that the volume of media coverage on a health issue (eg, infectious disease or tobacco control) is correlated with the likelihood of relevant policy adoption. ${ }^{8} 43$ In these studies, however, causality is hard to prove and even if the relationship were causal, the direction of the causality is unclear-higher coverage could stimulate policy action or policy action could lead to higher media coverage. ${ }^{43}$ Given Bangladesh's greater progress on MDG 5, our study suggests an association between the volume of newspaper coverage on maternal health issues and a country's trajectory towards MDG 5, though causality cannot be inferred.

While we cannot determine the nature of the association, one hypothesis is that the differences between each country's newspapers in their reporting on maternal health may reflect differences in the political and financial resources allocated to achieving MDG 5 between each country. In recent years, there has been a rise in global financial resources and political attention given to achieving MDG 5, with a focus mainly on lowincome countries. ${ }^{44}$ One major initiative, The Global Strategy for Women's and Children's Health, launched in 2010, has successfully mobilised high level political attention and significant financial and policy commitments for MDGs 4 and 5. ${ }^{14}$ The Global Strategy focuses on the 49 lowest-income countries, including Rwanda and Bangladesh, to ensure more investment in the health of women and children, thereby putting maternal health at the top of the political agenda in those priority countries. ${ }^{144}$ The Global Strategy also suggests that middle-income countries could mobilise enough domestic resources to finance their own maternal health needs. ${ }^{1}$ South Africa is an upper middle-income country, ${ }^{19}$ and thus is not on the priority list. Therefore, as shown in figure 1, the rise in DAH for maternal health directed towards Bangladesh and Rwanda could have played a role in their progress towards MDG 5. The focus of global initiatives on priority low-income countries may have influenced newspaper coverage of maternal health in Bangladesh and Rwanda, such as through greater reporting of international actors working in-country (eg, the WHO and the UN), or an increase in reporting of the relationship between global and national maternal health targets.

The prioritisation of low-income countries by global maternal health initiatives, such as The Global Strategy's focus on Bangladesh and Rwanda but not on South Africa, could have contributed to several important differences between each country's newspapers in the quantity and content of articles on maternal health. We found that from 2008 to 2012 there was a sharp increase in the annual number of articles published about maternal health in Bangladesh's The Daily Star and Rwanda's The New Times/The Sunday Times, with a much smaller rate of increase in South Africa's Sunday Times/The Times. The Daily Star and The New Times/The Sunday Times were more likely to include a higher profile protagonist (eg, prominent national political leaders, activists, WHO, UNFPA) than the Sunday Times/The Times. The Sunday Times/The Times often had a lower profile protagonist for maternal health, usually as part of a local or national programme, and was less likely to have a broader theme tying into the global MDGs movement. Furthermore, Bangladesh's The Daily Star and Rwanda's The New Times/The Sunday Times were more likely than South Africa's Sunday Times/The Times to explicitly 
discuss the connection between MDG 5 and improving maternal health within the country context; they were also more likely to directly mention a key cause of maternal mortality, or a proposed solution for maternal health.

\section{Differences in in-depth reporting on maternal health}

In-depth, evidence-based reporting of maternal health that is deeply researched can help to promote public health awareness and education, community mobilisation and political accountability for maternal health. ${ }^{45}$ It is therefore noteworthy that only Bangladesh's paper, The Daily Star, had any in-depth reporting at all (about 1 of every 7 articles were in-depth reports) and had the highest proportion of stories advocating for or raising awareness of maternal health. Most articles on maternal health in Rwanda's The New Times/The Sunday Times and South Africa's Sunday Times/The Times were short reports of events (eg, press conferences or meetings) or press releases published without additional investigation. A previous qualitative study of six 'media practitioners' (reporters, editors, producers and media managers) and six civil society representatives (activists, lawyers, students and religious representatives) in South Africa found that newspapers commonly based stories just on press releases. ${ }^{46}$ The key informants expressed concerns about South African media "regurgitating press releases without doing additional research or interviews." ${ }^{46}$ One key informant said: "We also rely too much on Google, and journalists are lacking basic knowledge. We follow Sapa (The South African Press Association), one another on Twitter...so we often make the same mistakes as one another." 46

The Daily Star exemplified in-depth coverage by initiating investigative reporting and roundtable forums featuring different organisations and experts. Such public discussion bridges potential gaps in knowledge, allows active promotion of maternal health concerns and creates a favourable environment for strong maternal health policymaking. By using minimal investigative reporting and neglecting to spearhead public discussions, The New Times/The Sunday Times and Sunday Times/ The Times missed an opportunity for greater impact.

\section{Differences in types of articles}

The proportion of articles on maternal health that were opinion-based was highest in Bangladesh's The Daily Star (37\%), followed by South Africa's Sunday Times/The Times (12\%) and then Rwanda's The New Times/The Sunday Times $(8 \%)$. Opinion-based articles provide a useful measure of public attitudes on social issues. ${ }^{47}$ In our sampled newspapers, opinion-based articles contained strong viewpoints, challenging or supporting the government's motivation for particular policy initiatives and shaping perceptions of solutions. While opinionbased articles are primarily written by authors who have enough knowledge to formulate a written response to particular issues, they can still provide a useful measure of general public attitudes on those issues. ${ }^{47}$

Our study did not set out to examine whether opinion-based articles influenced policy in Bangladesh. However, at least in theory, these types of articles could influence the public discourse on a health issue in ways that could reach health policymakers and possibly affect their decision-making. For example, opinion-based articles praising national progress on maternal health could have a 'positive feedback' effect, persuading policy makers to emphasise maternal health over other issues. Negative pieces that highlight preventable maternal deaths could exert bottom-up pressure on political leaders by raising awareness of the issues and informing officials to act. By swaying public opinion through opinion-based articles, these writers may have contributed to the discussion on maternal health in Bangladesh.

Recent news events relevant to maternal health often led to publication of letters to the editor. For example, in June 2012, a new abortion law came into effect in Rwanda as part of a larger review of Rwanda's penal code. ${ }^{48}$ The process of legalising safe abortion was a key national event that stimulated much media coverage; indeed, the topic of legalised abortion accounted for $15 \%$ of MDG 5-related articles published in The New Times/The Sunday Times during 2012. These letters are expressions of responses from members of the general public who opposed or supported the passage of such legislation. The New Times/The Sunday Times played a critical role in public deliberation of the issues by publishing both views in favour of and against safe abortion laws. This form of active media facilitation may have promoted greater public engagement with maternal health issues relevant to current affairs.

\section{Differences in framing}

A higher proportion of maternal health articles from Bangladesh's The Daily Star and Rwanda's The New Times/ The Sunday Times used rights-based or policy-based frames. Prior research on the interaction between media reporting and policymaking found that rights-based and policy-based media frames are associated with policy action. $^{7849}$ Policy-based frames describe a health issue within its broader social, economic and national context, increasing readers' sense of social responsibility and desire for policy action. ${ }^{49}$ Rights-based framing of maternal health can be a powerful stimulus for action, as this type of framing demands accountability for maternal deaths at the national level. ${ }^{7}$ In a recent case in Uganda, a well organised and active coalition of nongovernmental organisations (NGOs, called the Coalition to Stop Maternal Mortality in Uganda sued the government over the deaths of two women during childbirth, deaths that could have been averted, citing a violation of their constitutional right to health. ${ }^{50}$ The NGOs drew significant public attention to the issue of avertable maternal deaths by arguing that the right to health guarantees access to quality care, and that negligence by 
Ugandan authorities causes thousands of maternal deaths annually. ${ }^{50}$ While a causal link cannot be proven from our study, it is possible that the rights-based and policy-based framing of articles in The Daily Star and The New Times/The Sunday Times played a similar role in stimulating action on MDG 5.

South Africa's constitution guarantees the right to healthcare, ${ }^{19}{ }^{20}$ and so it is surprising that many articles on maternal health in South Africa's Sunday Times/The Times framed their stories through a moral/ethical framing $(39 \%)$ rather than primarily favouring a human rights lens (only $41 \%$ ), particularly when covering teen pregnancy and hospital scandals. Previous studies have shown that moral/ethical framing is less likely than rights-based framing to generate significant funding and attention for neglected health issues. ${ }^{8}$ These framing differences may have affected the political attention and financial resources directed to maternal health in each country-though again, this conclusion cannot be drawn from a cross-sectional study such as ours.

\section{Differences in tone}

Almost two thirds of articles on maternal health in South Africa's Sunday Times/The Times had a negative tone, focusing on healthcare scandals, failed abortions and poorly funded hospitals. Such a negative tone, while highlighting important public health concerns, may deter individual citizen action by portraying it as an 'unsolvable problem, ${ }^{51}$ This tone may also discourage women from seeking reproductive or maternal healthcare, such as by frightening women about the poor quality of maternal health services. Prior research has shown that while negatively framed or 'fear-framed' issues initiate greater attention and potential for behaviour change, they can impair decisive action to reduce dangerous outcomes, particularly if no clear and effective solution is provided or if subjects feel that they have no control over preventing a negative outcome. ${ }^{52}$ More balanced reporting can emphasise priority issues while still encouraging safe maternal and reproductive health practices.

\section{Differences in context}

All three newspapers connected specific national concerns to maternal health interventions. Bangladesh, the world's most densely populated country, ${ }^{14}$ has long been concerned by its rapid population growth. Bangladesh's The Daily Star often discussed family planning in the context of slowing population growth. In comparison, The New Times/The Sunday Times of Rwanda and Sunday Times/The Times of South Africa emphasised family planning to reduce adolescent pregnancy, a significant concern in these two countries. As mentioned previously, The New Times/The Sunday Times also frequently published on abortion, stimulated by the recent passage of a safe abortion law in 2012. ${ }^{48}$ Our results suggest that the solutions that are presented for solving health problems across different newspapers are contextdependent and country-dependent.

\section{Conclusions and policy implications}

Our study suggests that there may be a link between a country's progress towards MDG 5 and the frequency, tone and content of its newspaper coverage of maternal health. Given previous research showing an association between media coverage of a global health problem and policy attention towards that problem, it is possible that greater media attention towards maternal health could be linked with maternal health being positioned higher on the agenda for policy action.

The differences in reporting highlighted by our study, such as the use of policy-based framing and opinionbased articles, could potentially be valuable to those who are trying to engage the media in maternal survival efforts. The Daily Star of Bangladesh has been able to highlight maternal health issues by organising seminars, discussions and roundtables, which are then covered in the newspaper-a strategy that could be valuable for other countries to replicate. In addition, the way in which news articles are framed can influence whether policymakers take action. Rights-based and policy-based framing is likely to be more effective than moral or ethical framing at stimulating government action, as it fosters accountability and can help to shift perceptions of a health issue among the general public and policymakers. Opinion-based articles written by citizens, organisations and civil society groups that draw attention to maternal deaths and propose potential solutions can create a public discourse that is conducive to policy action. Lastly, as seen with the possible link between the UN's Global Strategy for Women's and Children's Health and national action on maternal health in Rwanda and Bangladesh, aligning national and global efforts while reporting on maternal health issues could catalyse solidarity, attention, funding and progress towards MDG 5.

It is unclear to what extent these findings may be generalisable to other settings, given the importance of country context in both improving maternal health and in media representations of health. Nevertheless, we included three countries from three different categories in the Countdown to 2015 report (on track; some progress, but not on track; and no progress). The differences that we found between Bangladesh, Rwanda and South Africa might also be seen between three other countries that come from these three different category groupings.

\section{Next steps}

The limitations of our study could be addressed by future research that examines a broader range of media, including native language newspapers, radio and television, and research that examines the influence of media coverage of maternal health on actual maternal health policies. Our next study will be a qualitative study of reporters and editors from The Daily Star, The New Times/ The Sunday Times and Sunday Times/The Times-the public opinion 'gate-keepers ${ }^{53}$ - to explore their views 
on the facilitators and barriers to covering maternal health stories.

Acknowledgements The authors thank John Ziegler (University of California, San Francisco; UCSF), and Megan Tan (Stanford University) for their thoughtful comments and review of an early draft of this manuscript; Wayne Enanoria (UCSF) for providing assistance in the statistical analysis of our study; Nancy Fullman (Institute for Health Metrics and Evaluation) for providing us the data on development assistance for maternal health for Bangladesh, Rwanda and South Africa; and the two external peer reviewers, Calistus Wilunda (School of Public Health, Kyoto University, Japan) and Cynthia Summers, (Guttmacher Institute, USA), for their valuable comments on two earlier versions of this paper.

Contributors FG conceptualised the study, led all aspects of its implementation and wrote the first draft of the article. EK contributed to study design, data collection, article coding, interpretation of the findings and the second draft of the article. AC contributed to study design, data analysis and the second draft of the article. GY, the Principal Investigator, contributed to study design, supervised all aspects of the study, and contributed to writing the second draft of the article.

Competing interests GY declares that his research has been funded by several donors and non-profit organisations that work to reduce maternal deaths: the Bill and Melinda Gates Foundation, the Clinton Health Access Initiative, the Global Fund, the Partnership for Maternal, Newborn and Child Health, the UK Department for International Development, the Norwegian Agency for Development Cooperation, and UNITAID.

Ethics approval Institutional review board approval was not necessary for this study because the data were obtained from publicly available newspaper articles.

Provenance and peer review Not commissioned; externally peer reviewed.

Data sharing statement Extra data can be accessed via the Dryad data repository at http://datadryad.org/with the doi:10.5061/dryad.83004

Open Access This is an Open Access article distributed in accordance with the Creative Commons Attribution Non Commercial (CC BY-NC 4.0) license, which permits others to distribute, remix, adapt, build upon this work noncommercially, and license their derivative works on different terms, provided the original work is properly cited and the use is non-commercial. See: http:// creativecommons.org/licenses/by-nc/4.0/

\section{REFERENCES}

1. Schrade C, Schäferhoff M, Yamey G, et al. Strengthening the global financing architecture for maternal, newborn and child health: options for action. Partnership for Maternal, Newborn and Child Health, 2011.

2. WHO and UNICEF. Countdown to 2015. Building a future for women and children. World Health Organization and UN Children's Fund, Geneva; 2012

3. Family Planning Summit. 2012. http://www.who.int/pmnch/media/ news/2012/20120627_family_planning_summit/en/index.html (accessed 23 Oct 2015).

4. Dreser A, Vázquez-Vélez E, Treviño S, et al. Regulation of antibiotic sales in Mexico: an analysis of printed media coverage and stakeholder participation. BMC Public Health 2012;12:1051.

5. Thapa S. Abortion Law in Nepal: the road to reform. Reprod Health Matters 2004;12(24 Suppl):85-94.

6. Menashe CL, Siegel M. The power of a frame: an analysis of newspaper coverage of tobacco issues-United States, 1985-1996. $J$ Health Commun 1998;3:307-25.

7. Bueno de Mesquita J, Kismödi E. Maternal mortality and human rights: landmark decision by United Nations human rights body. Bull World Health Organ 2012;90:79A.

8. Hudacek DL, Kuruvilla S, Kim N, et al. Analyzing media coverage of the global fund diseases compared with lower funded diseases (childhood pneumonia, diarrhea and measles). PLOS ONE 2011;6: e20438.

9. Balasegaram M, Balasegaram S, Malvy D, et al. Neglected diseases in the news: a content analysis of recent international media coverage focussing on leishmaniasis and trypanosomiasis. PLOS Negl Trop Dis 2008;2:e234.
10. Campbell $\mathrm{O}$, Gipson $\mathrm{R}$, Issa $\mathrm{AH}$, et al. National maternal mortality ratio in Egypt halved between 1992-93 and 2000. Bull World Health Organ 2005;83:462-71.

11. Hutchinson $P$, Meekers D. Estimating causal effects from family planning health communication campaigns using panel data: the "your health, your wealth" campaign in Egypt. PLOS ONE 2012;7: e46138.

12. Worldbank.org. Harmonized list of fragile situations 10. 2010. http:// pubdocs.worldbank.org/pubdocs/publicdoc/2014/9/ 963681410886171483/FY10toFY13Harmonized-list-FragileSituations.pdf (accessed 1 Mar 2013).

13. Takrouri M. Reproductive health: the issues of maternal morbidity and mortality. Internet $J$ Health 2004. http://ispub.com/lJH/3/2/6236 (accessed 1 Dec 2012)

14. El Arifeen S, Hill K, Ahsan $\mathrm{K}$, et al. Maternal mortality in Bangladesh: a Countdown to 2015 country case study. Lancet 2014;384:1366-74.

15. Dieleman J, Graves C, Johnson E, et al. Sources and focus of health development assistance, 1990-2014. JAMA 2015;313:2359-68.

16. Nsanzimana S, Prabhu K, McDermott $\mathrm{H}$, et al. Improving health outcomes through concurrent HIV program scale-up and health system development in Rwanda: 20 years of experience. BMC Med 2015;13:216.

17. Condo J, Mugeni C, Naughton B, et al. Rwanda's evolving community health worker system: a qualitative assessment of client and provider perspectives. Hum Resour Health 2014;12:71.

18. Lawn J, Kinney M. Health in South Africa: Executive Summary of the Series. Lancet 2009;374:2-6.

19. Coovadia $\mathrm{H}$, Jewkes R, Barron $\mathrm{P}$, et al. The health and health system of South Africa: historical roots of current public health challenges. Lancet 2009;374:817-34.

20. Bilchitz D. South Africa: Right to health and access to HIV/AIDS drug treatment. Int J Constitutional Law 2003;1:524-34.

21. Chopra M, Lawn J, Sanders D, et al. Achieving the health Millennium Development Goals for South Africa: challenges and priorities. Lancet 2009;374:1023-31.

22. National Institute of Population Research and Training (NIPORT), Mitra and Associates, and ICF International. Bangladesh demographic and health survey 2011. Dhaka, Bangladesh and Calverton, MD, USA: NIPORT, Mitra and Associates, and ICF International, 2013.

23. National Institute of Statistics of Rwanda (NISR) [Rwanda], Ministry of Health (MOH) [Rwanda], and ICF International. Rwanda demographic and health survey 2010. Calverton, MD, USA: NISR, $\mathrm{MOH}$, and ICF International, 2012.

24. Department of Health, Medical Research Council, OrcMacro. South Africa demographic and health survey 2003. Pretoria: Department of Health, 2007.

25. Department of Health, Medical Research Council, and Macro International. South African demographic and health survey 1998. Pretoria, South Africa: Department of Health, 1998.

26. Holder $\mathrm{H}$, Treno A. Media advocacy in community prevention: news as a means to advance policy change. Addiction 1997:92:189-200.

27. Strömbäck J, Kiousis S. A new look at agenda-setting effects-comparing the predictive power of overall political news consumption and specific news media consumption across different media channels and media types. $J$ Commun 2010;60:271-92.

28. D'Angelo P, Pollock JC, Kiernicki K, et al. Framing of AIDS in Africa: press-state relations, HIV/AIDS news, and journalistic advocacy in four sub-Saharan Anglophone newspapers. Politics Life Sci 2013;32:100-25.

29. Hossain M. The Impact of English Language on the Lifestyle and Behavior of Tertiary Level Students in Bangladesh: Case Study 1499 Jahangirnagar University. GJHSS-G: Linguist Educ 2013 http://socialscienceresearch.org/index.php/GJHSS/article/view/728/ 675 (accessed 1 Sept 2015).

30. Islam M. Print media and governance in Bangladesh: a critical reading. Asian Politics Policy 2015;7:341-4.

31. High Council of the Press. Analysis on professionalism in Rwandan media. Kigali, Rwanda: Rwanda Media Monitoring Project (RMMP), 2004.

32. Jacobs S, Johnson K. Media, social movements and the state: competing images of HIV/AIDS in South Africa. Afr Stud $Q$ 2007;9:127-52.

33. Riffe D, Aust C, Lacy S. The effectiveness of random, consecutive day and constructed week sampling in newspaper content analysis. $J$ Mass Commun Q 1993;70:133-9. 
34. Altheide D. Reflections: Ethnographic content analysis. Qual Sociol 1987;10:65-77.

35. Rahman Jony M. Achieving MDG-5 by 2015. The Daily Star 2012 http://archive.thedailystar.net/newDesign/news-details.php? nid=248381 (accessed 1 May 2013)

36. Umutesi D. Addressing reproductive behaviour issues among Rwanda's youth. The New Times 2012. http://www.newtimes.co.rw/ section/article/2012-02-29/50034/ (accessed 29 Feb 2012).

37. Keya K. More trained midwives, more lives saved. The Daily Star 2011. http://archive.thedailystar.net/newDesign/news-details.php? nid=192402 (accessed 3 May 2013).

38. Govender P, Mahlangu I. 50 SA nurses 'named, shamed'. Sunday Times 2012. http://www.timeslive.co.za/sundaytimes/2012/06/10/ 50-sa-nurses-named-shamed (accessed 18 May 2013).

39. Kabeera E. Rwanda tops region in infant, maternal health. The New Times 2010. http://www.newtimes.co.rw/section/article/2010-11-01/ 25496/ (accessed 14 May 2013).

40. The Daily Star. ABOUT US. http://www.thedailystar.net/about-us (accessed 17 Feb 2014).

41. The Daily Star. Govt to recruit 13,000 family planning staff. 2013 . http://archive.thedailystar.net/newDesign/news-details.php? nid=211564 (accessed 1 May 2011)

42. Kaitesi M, Karuhanga J. Mixed reactions as legislation on abortion go to Senate. The New Times 2012. http://www.newtimes.co.rw/ section/article/2012-04-09/51488/ (accessed 6 May 2013).

43. Asbridge M. Public place restrictions on smoking in Canada: assessing the role of the state, media, science and public health advocacy. Soc Sci Med 2004;58:13-24.

44. Schrade C, Yamey G, Schäferhoff M. Packages of care-A pragmatic approach to exploring an enhanced role for the Global
Fund in Maternal, Newborn and Child Health (MNCH). The Evidence to Policy Initiative (E2Pi), 2010.

45. Building Media Capacity: To Cover Population and Reproduction Health. Population Reference Bureau. 2010. http://www.prb.org/ pdf10/bridge-media (accessed 24 Sep 2013).

46. African Media Barometer South Africa. Friedrich-Ebert-Stiftung. 2013. http://www.fesmedia-africa.org/uploads/media/AMB_SA_web_ version_2013.pdf (accessed 18 May 2013).

47. Smith KC, McLeod K, Wakefield M. Australian letters to the editor on tobacco: triggers, rhetoric, and claims of legitimate voice. Qual Health Res 2005;15:1180-98.

48. Umuhoza C, Oosters B, van Reeuwijk M, et al. Advocating for safe abortion in Rwanda: how young people and the personal stories of young women in prison brought about change. Reprod Health Matters 2013;21:49-56.

49. McKeever B. News framing of autism: understanding media advocacy and the combating autism act. Sci Commun 2013;35:213-40.

50. Benedetti F, Kijo-Bisimba H. Women's rights in Uganda: gaps between policy and practice. FIDH—International Federation for Human Rights. 2012. https://www.fidh.org/IMG/pdf/uganda582afinal. pdf (accessed 10 May 2013).

51. Feinberg M, Willer R. Apocalypse soon? Dire messages reduce belief in global warming by contradicting just-world beliefs. Psychol Sci 2011;22:34-8.

52. Witte K, Allen M. A meta-analysis of fear appeals: implications for effective public health campaigns. Health Educ Behav 2000;27:591-615.

53. Durrant R, Wakefield M, McLeod K. Tobacco in the news: an analysis of newspaper coverage of tobacco issues in Australia, 2001. Tob Control 2003;12:75ii-81. 